\title{
O CONCEITUALISMO LÚDICO DE BAS JAN ADER: PERFORMANDO A IDENTIDADE TRANSICIONAL
}

\author{
REVISITING BLACKMOUNTAIN COLLEGE. \\ TEACHING TO TRANSGRESS
}

Janna Schoenberger

University of Amsterdam

Tradução

Angela Grando

PPGA-UFES

Léa Araújo

UFES

Profa. Dra. Janna Schoenberger atua como professora da University of Amsterdam. Concluiu seu PhD no Graduate Center, na City University of New York com a tese Ludic Conceptualism: Art and Play na Holanda de 1959 a 1975." Recentemente, Dra. Schoenberger concluiu bolsas no Rijksmuseum e na Biblioteca Beinecke da Universidade de Yale. Seu livro, Waiting for the Witch Doctor: Robert Jasper Grootveld's Scrapbook and the Dutch Counterculture, foi publicado pelo Rijksmuseum em 2020. Este artigo foi publicado originalmente pela John Benjamins Publishing Company no ano de 2015.

Resumo: Seguindo as ideias de Huizinga em sua obra Homo Ludens (1938), proponho o termo Conceitualismo Lúdico para descrever a arte que floresceu em solo holandês dentre os anos de 1959 a 1975. Diferentemente da vertente mais austera do conceitualismo desenvolvido em Nova York e Reino Unido, o jogo era central para a vertente holandesa. Neste artigo discutirei como a consolidação de uma identidade, performada através de piadas de cunho satírico baseadas em estereótipos nacionais, se tornou a chave para a compreensão do processo artístico do artista conceitual holandês Bas Jan Ader. Embora grande parte do humor presente em seu trabalho seja óbvio, não houve nenhuma investigação séria sobre sua prática da ironia. Posicionarei Ader dentro da estrutura da arte conceitual humorística pós-guerra prevalecente na Holanda e Califórnia, localidades onde Ader viveu e estudou. Utilizando teorias do humor e da identidade demonstrarei como as piadas de Ader estão intrinsecamente ligadas a contextos sociais presentes nos dois lados do Atlântico, ambientes relevantes para o desenvolvimento artístico em todo curso de sua curta carreira. Uma investigação atenta sobre o trabaIho de Ader revelará que a identidade densa desse artista, como vista em sua utilização do humor, é de fato, a característica central de seu trabalho. 

pelo foco não em seu trabalho, mas em seu não usual modo de falar. Nahuizen observou que Ader usava muitas palavras em inglês, e falava seu dialeto natural de Groningen com sotaque norte americano. O repórter conclui que o tempo passado pelo artista nos Estados Unidos o havia tornado arrogante, alegação conectada a suposta dificuldade de Ader em falar holandês. Uma fala de Ader foi citada (talvez, influenciado pelo entrevistador) "Eu não sou Groninger nem holandês, mas também não sou um americano. Eu não quero ser nada além de Bas Jan - eu mesmo." (Nahuizen, 1961). ${ }^{3}$

Quem era Bas Jan Ader? Sua identidade imprecisa e híbrida, refletida em seu uso do humor, é de fato a característica central de seu trabaIho. Neste artigo, especificamente, mostrarei como compreender a fixação de Ader em sua identidade transcultural performada, através de sátiras de estereótipos nacionais e tropos, é vital para abranger sua produção artística.

Até o presente momento não houve uma investigação séria sobre o aspecto cômico presente na obra de Bas Jan Ader. Os escritos sobre este artista são focados especificamente no caráter trágico de sua vida, como a execução de seu pai durante a Segunda Guerra Mundial ou, ainda, sobre sua misteriosa morte no mar, em 1975. Ader foi situado em uma tradição de Romantismo melancólico, cotejando figuras como o pintor alemão Caspar David Friedrich (Verwoert 2006; Sefermann et al.2008) ${ }^{4}$. De outro modo, parto do princípio que Ader deveria

3 "Groninger": Termo que se refere aos que nascem no condado de Groningen. Groningen foi uma terra independente que se juntou à Holanda em 1594. Teve um destaque histórico, sendo uma cidade comercial cujo dialeto tornou-se uma língua oficial na região. (nota da tradutora)

4 Caspar David Friedrich (1774-1840) foi um dos mais eminentes representantes do Romantismo, movimento cultural surgido ao final do século XVIII e que se estendeu aproximadamente até meados do século XIX. ser inserido no contexto da arte conceitual de caráter humorístico evidenciada no pós-guerra, a qual prevaleceu tanto na Holanda quanto na Califórnia, localidades onde o artista viveu e estudou. Assim, explorarei o uso do humor, desenvolvido na Costa Oeste norte- americana a partir de sua posição periférica na arte mundial e, ainda, o porquê de a Holanda ser particularmente receptiva à arte lúdica. Utilizando teorias do humor e da identidade, mostrarei como a estética bem humorada e lúdica de Ader é fortemente ligada à percepção crítica dos contextos sociais presentes dos dois lados do Atlântico, ambientes relevantes para o desenvolvimento da arte em todo curso de sua curta carreira.

O historiador cultural holandês Johan Huizinga, em um de seus livros mais renomados, Homo Ludens: O jogo como elemento da cultura, publicado em 1938, ${ }^{5}$ interpretou elementos presentes no instinto do jogo e argumentou que o jogo é um elemento formativo da cultura e está presente em quase todas as expressões culturais $(1971)^{6}$. Linguista de coração, Huizinga achou que a melhor palavra para descrever a inquisitiva childlike, e inerentemente moral do jogo era a palavra em Latim ludus, de onde advém a titulação de seu livro. Concordando com Huizinga,

5 O livro foi publicado originalmente em 1938, entretanto a autora utiliza como referência a versão publicada em 1976. (nota da tradutora)

6 A tradução em inglês amplamente disponível sintetiza as traduções de Huizinga, em 1944, para o alemão e inglês. No "Prefácio" Huizinga esclarece que o subtítulo deveria ser "The Play Element of Culture" mas o tradutor não identificado o adaptou para "The Play Element in Culture" e o justificou como "mais eufônico".

7 Em estudo mais recente sobre Huizinga e seu trabalho, veja Willem Otterspeer, Reading Huizinga, trans. Beverly Jackson (Amsterdam University Press, 2011). O título Homo Ludens, homem o jogador, é uma resposta direta ao marxismo - homo farber, homem criador. Huizinga argumentou que o peso dado as forças econômicas no curso do mundo pelos marxistas foi um "equívoco vergonhoso". Huizinga,

Homo Ludens, 192. 
uso o termo "lúdico" para descrever a tendência de uma arte playfull popular na Holanda e na Costa Oeste dos Estados Unidos nas décadas de 1960 e início de 1970. Diferentemente das mais rigorosas, burocráticas e tautológicas amarras do conceitualismo desenvolvido em Nova York (como o de Joseph Kosuth), o humor é central nesse cenário na Holanda e na Califórnia. Assim, proponho o termo de conceitualismo lúdico como o mais apropriado para discutir a obra de Bas Jan Ader e de outros nessa linha.

O humor permeou a arte produzida e exposta na Holanda durante a década de 1960. Uma afeição à ludicidade conecta uma variedade de designs, fotografias, filmes e performances. Por exemplo, a Nova Babilônia de Constant Nieuwenhuis, um plano para uma cidade utópica como um playground infinito, foi exibido pela primeira vez em Amsterdam, em 1959. Nessa cidade utópica proposta, cidadãos não seriam obrigados a trabalhar, ao invés disso viveriam como seres criativos; isto é, sua existência e significado seriam vivificados em suas contribuições sociais antirracionais e antifuncionais. Dois anos depois, Win T. Schippers realizou uma performance televisionada, esvaziando uma garrafa de refrigerante soda dentro do mar. Em uma série de trabalhos executados em 1961, o artista Stanley Brouwn propôs um novo método de construção de mapas que refletiriam melhor nos indivíduos a experiência subjetiva de navegar na cidade: This Way Brouwn, No Way Brouwn, Brouwn This Wat Public e This Way Brouwn for the Soul, todas envolvendo pedestres e direções traçadas para localidades existentes ou não na cidade de Amsterdam.

Os holandeses não foram os únicos a aderirem ao humor: a Califórnia também produziu uma onda de arte lúdica nesse período, especialmente no conceitualismo. Portanto, não é surpresa que os artistas conceituais da Califór- nia, incluindo John Baldessari e Allen Ruppersberg, tenham sido bem recebidos na Holanda: ambos tiveram exibições individuais em Amsterdam nos anos de 1972 e 1973, respectivamente. O humor era um modo de expressão popular em Los Angeles, tanto devido à presença da indústria do entretenimento como à relativa falta da mídia crítica especializada, especialmente se comparada ao cenário crítico de Nova York (Baldessari, 2011) ${ }^{8}$. De acordo com Ann Goldstein, procedente de Los Angeles e antiga diretora do Museu Stedelijk de Amsterdam, o foco de L.A seria o entretenimento, e de tal modo, que esta cidade se configurou um ótimo local para alguém se tornar um artista porque "ninguém ligava para você" (Larry Bell e Ann Goldstein 2013). Em Nova York artistas poderiam ter certeza de que cada trabalho de arte ou declaração seriam analisados e examinados atentamente, levando a uma ponderação de auto seriedade por parte da comunidade artística. Em Los Angeles, por contraste, a falta de mídia crítica permitiu aos artistas a liberdade do jogo. (Baldessari 2011). ${ }^{9}$

Por que museus e galerias holandeses foram tão receptivos ao conceitualismo lúdico, especialmente aquele oriundo de Los Angeles, e por que a arte conceitual lúdica se espalhou tão facilmente pela Holanda? Assim como Los Angeles estava em relação a Nova York, Amsterdam ocupava uma posição periférica no que diz respeito à hegemonia artística parisiense. 0 humor era peça central na estratégia crítica não apenas para artistas holandeses, mas também

8 John Baldessari em conversa com Ann Goldstein e Rudi Fuchs, tentaram articular porque o humor era uma força motriz.

9 Na mesma conversa Rudi Fuchs comenta sobre sua apreciação do humor presente no trabalho de Baldessari, Bruce Nauman, e Sol LeWitt, que é bem representado no Museu Stedelijk de Amsterdam. Fuchs se refere a LeWitt como "mestre cômico". 
para ativistas políticos holandeses que recorriam ao potencial satírico para provocar a ordem social vigente. Em meados dos anos 1960, o movimento anarquista Provos tentou chamar atenção para o trânsito e o tráfego congestionado na cidade, defendendo a distribuição gratuita de bicicletas pintadas de branco por toda Amsterdam, o que se tornou conhecido como o "plano das bicicletas brancas" ${ }^{10}$. O Provos recorreu a uma série de táticas lúdicas provocativas para confrontar tanto o governo conservador holandês, quanto a grande parcela da população conformista de classe média - por exemplo, a fim de chamar atenção para a maneira que Amsterdam priorizava carros em oposição a ciclistas e pedestres, eles distribuíram groseIhas no meio da rua para perturbar o trânsito. Seguindo a tradição do humor satírico o Provos zombou de convenções sociais, e nessa instância se expressaram contra a cultura automobilística crescente em Amsterdam. Finalmente, os artistas holandeses estavam se conectando a longa tradição de humor e de sátira na arte e na literatura, herdeira de uma prática cultural que recua ao final do século XV; para tal, basta apenas lembrar do artista Hieronymus Bosch e do estudioso humanista Erasmu's em "Elogio da Loucura", juntamente a diversos outros exemplos. Ader era, portanto, parte de uma geração holandesa e norte americana que adotou o humor e a sátira como prática artística.

É proveitoso examinar a natureza satírica do trabalho de Ader através das lentes da teoria da incongruência. De acordo com essa teoria, atualmente dominante em estudos sobre o humor, o humor é encontrado em uma coisa

10 Provos - foi um conglomerado de jovens holandeses atuantes entre os anos de 1965 e 1967. Durante os anos que estavam em atividades manifestaram sua insatisfação social de maneira pacífica e lúdica, através de panfletos, periódicos, planos e happenings. (nota da tradutora) ou evento que viola padrões mentais e expectativas (Morreall 2009). O filósofo Simon Critchley ainda postula que existe uma espécie de contrato social implícito entre o humorista e a audiência, pois para a compreensão da incongruência deve haver primeiro a congruência. Se a congruência não está presente, o humor não se torna engraçado (Critchley 2004: 4). Isso explica, por exemplo, porque é tão difícil contar uma piada em uma língua estrangeira: o humor tende a ser local, especificamente contextualizado, e uma forma de conhecimento intrínseco (ibid.: 67). De acordo com Critchley. "A doce melancolia do exílio está frequentemente enraizada na nostalgia da perda do senso de humor" (ibid.:68). Ele adiciona que o humor que nos traz de volta para casa, ou ao que nós sabemos frequentemente, faz isso relacionando conjuntamente ansiedade, dificuldade e vergonha (ibid.:74). A sátira só funciona com uma base cultural comum, ou congruência, e o humor na sátira existe no ataque a crenças compartilhadas.

Como um imigrante holandês no sul da Califórnia, Bas Jan Ader usou o humor para expressar as dificuldades de viver entre duas nações; sua terra natal e a sua morada escolhida nos Estados Unidos. Ader, de uma maneira satírica, utilizou clichês e estereótipos das duas nações em seus desenhos, filmes e fotografias. No seu uso da sátira, Ader olha para sua própria experiência vivida e identidade como fonte para questionar as normas sociais. Seu livro de artista - publicado quando de sua exposição de conclusão de Mestrado em Belas Artes na Claremont Graduate School, na Califórnia, em fevereiro de 1967- está repleto de trocadilhos que, provavelmente, apenas seus colegas holandeses conseguiriam entender. Por exemplo, ele escreveu e ilustrou um conto para o livro intitulado "What makes me so pure, almost holy? And more." sobre as aventuras de um holandês e 
sua amiga Béa - apelido da então princesa (e até recentemente rainha) Béatrix- que, entre outras coisas, tenta mover um pesado trono. Na imagem em oposição, na primeira página, o nome Béa Bloemkool está inscrito num mapa abstrato da Holanda. Ademais, ao humor de aliteração, o nome (bloemkool significa couve-flor) remete jocosamente à cidade natal de Ader, província rural de Groningen, onde as couves-flores são uma cultura típica e ingrediente em pratos tradicionais. Provavelmente, não coincidentemente, couve-flor também era uma gíria grosseira para seios. (Mais conhecida pelo seu uso na canção do comediante e compositor André van Duin, no ano de 1979, denominada "Ok Heb Hele Grote Bloemkolen"). ${ }^{11}$ Embora Ader tenha escrito essa curta história em inglês, ele escolheu uma palavra holandesa para aliterar na nomenclatura de Béa; e não apenas qualquer palavra holandesa, mas a que remete ao humor sexista utilizado em sua terra natal. Ader também distinguiu visualmente sua região natal com uma estrela sobre Groningen em seu mapa da Holanda. Assim, vale a pena questionar: quem entendeu a piada? Notavelmente, seu compatriota exilado e amigo, o holandês Ger van Elk deve ter sido parte da referida audiência (Daalder 2008). A escolha de Ader em utilizar um humor específico do norte da Holanda indica uma certa nostalgia e saudade de sua província natal.

Em um poema no mesmo livro de artista, "What does it mean? Cheep cheep?", Ader articula ainda mais sua saudade de casa. No final da primeira página, o artista explica que o poema é sobre "hoje e ontem" significando sua vida entre a Califórnia e a Holanda. Ader era aparentemente feliz em sua casa de madeira e notou que "a grama era mais verde do outro lado". ${ }^{12}$ Neste li-

11 "Ok Heb Hele Grote Bloemkolen" - eu tenho grandes couves-flores.

12 Correspondente ao ditado em português "a grama do vro, podemos notar Ader, escrevendo como um expatriado na Califórnia, dissimulando sua saudade de casa com humor enraizado na Holanda.

Quatro anos após sua exibição no MFA, Ader retornou a Holanda e seu processo criativo reflete uma sensibilidade que não era apenas estadunidense, mas distintamente californiana ${ }^{13}$. O termo "California Slapstick" ${ }^{14}$, formulado por Jay Leyda em 1985, define um modo particular de humor associado ao mundo imaginário do emergente estado do oeste, como visto, por exemplo, em filmes de Buster Keaton e Harold Lloyd (Federação Internacional de Arquivos Cinematográficos 1988; Wolfe 2010; 169-190). Ader evocou California Slapstick no trabalho de arte executado na Holanda no início da década de 1970. Críticos identificaram o seu uso de slapstick e suas alusões a Keaton (Schorr 1994: 37; Steenbergen 1993; Andriesse 1998), mas até o presente momento ninguém tentou compreender como a vertente humorística se relaciona a uma identificação simultânea com dois países.

Uma comédia ao estilo Keaton é facilmente reconhecida nos filmes Fall de Ader, o que revela um senso de humor influenciado pelo humor californiano e, possivelmente, uma correspondente mudança em seu senso de identidade. Por exemplo, ao considerar o Fall II (Amsterdam) de 1970, filmado em uma rua de Amsterdam. Nele o artista aparece em uma bicicleta, segurando um punhado de flores, antes de pedalar lentamente até adentrar o canal. É o puro slapstick, referenciando o fatídico acidente de carro em uma vala, presente no filme de Buster Keaton, de 1923, "As Três Idades". Aqui, Ader

vizinho é sempre mais verde". (nota da tradutora)

13 MFA (Master of Fine Arts) referente a exposição de conclusão do mestrado citada anteriormente nesse texto. (nota da tradutora)

14 Equivalente ao tipo de humor conhecido popularmente no Brasil como "Comédia Pastelão". (nota da tradutora) 


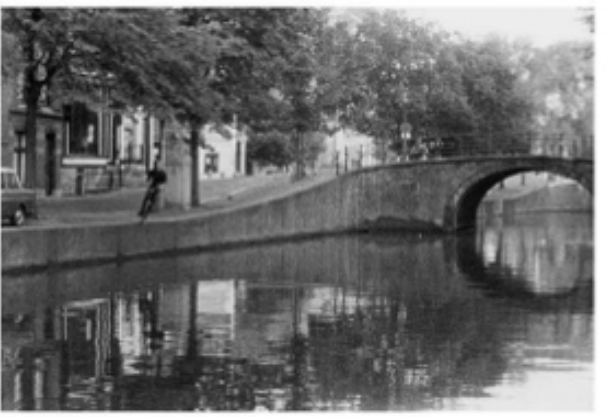

abandonou as referências de Groningen presentes em seu livro de 1967, enquanto explora clichês holandeses óbvios como: flores, canais e bicicletas. Entre o final da década de 1960 os primeiros anos de 1970, o humor de Ader transita nas evocações nostálgicas de seu local de nascimento para englobar (zombar de) sua terra natal recuperada. Enquanto em seu livro de artista vemos uma aspiração por sua terra natal com observações satíricas baseadas em piadas de Groningen, apenas alguns anos depois Ader estava usando o slapstick para gracejar com estereótipos holandeses.

Em diversos outros trabalhos, da mesma época, as alusões estereotipadas à Holanda aparecem e abarcam novamente o uso do California slapstick; conquanto, o assunto transmude de bicicletas e canais para um tropo da arte holandesa: De Stijl. Um exemplo claro é Broken Fall (Geometric), Westkapelle, Holland (1971). O filme mostra Ader em uma estrada de paralelepípedos que leva a um farol e, no trajeto, tombando em um cavalete devido uma extrema ventania. Nesse contexto, a astuta alusão é ao artista holandês por excelência Piet Mondrian. Mondrian fez parte do movimento De Stijl no período de 1917 a 1925, interrompendo sua participação no grupo em razão de sua desavença sobre o uso formal de diagonais. Ademais, Mondrian pintou esse farol diversas vezes, realizando experimentações com a redução de cores, que o levou eventualmente a sua paleta de cores primárias. Em uma entrevista no ano de 1971, Ader afirmou que a terra e a torre de água eram os elementos horizontais e verticais presentes nas pinturas de Mondrian, enquanto que o cavalete e a ação de queda representavam as diagonais incorporadas por Mondrian (Van Garrel 1972: 48). Ader desta maneira recriou uma pintura sob a formalidade De Stijl e, em seguida, desvirtuou-a, ao mesclar as diagonais de Mondrian, em uma dualidade de homenagem e sabotagem. Tal como acontece com Fall II (Amsterdam), Ader aqui in corporou o humor California slapstick em um cenário típico holandês. O trabalho de Ader pode ser visto como um autorretrato incorporando e performando sua identidade binacional. Enquanto o filme Broken Fall (Geometric) indi- Pictures - New York. ca uma aquiescência conceitual ao De Stijll, seu On the Road to a New Neo Plasticism, Westkappel Holland de 1971 pode ser visto como uma citação formal do movimento De Stijll. Nessa série de quatro fotografias Ader fisicamente se constrói dentro de uma composição abstrata do De Stijll; para isto, se transforma em linhas pretas verticais e horizontais sequencialmente adicionando objetos de cores primárias para formar uma versão de uma pintura de Piet Mondrian. Talvez possamos ler On the Road to a New Neo Plasticism, Westkappel Holland como uma interpretação contemporânea de tableau vivant. Uma posterior exploração das cores primárias referenciando a arte holandesa é o vídeo Primary Time (1974) no qual Ader gradualmente rearranja um vaso de flores até o agrupamento mudar de inteiramente vermelho para amarelo e finalmente para azul. ${ }^{15}$ Novamente, Ader está combinando um tropo holandês - neste caso, flo-

15 Primary Time é um vídeo de 1974 e foi feito simultaneamente ao Untlited (Flower work), a série fotográfica do mesmo ano.
Figura 2 Bas Jan Ader - Studies for Fall 2, Amsterdam, 1970. Set of three black and white vintage prints, $31 / 2 \times 5$ inches; $8.9 \times 12.7 \mathrm{~cm}$ (each image) unique. (c) The Estate of Bas Jan Ader / Mary Sue Ader Andersen, 2016 / The Artist Rights Society (ARS)-New York, Courtesy Meliksetian| Briggs - Los Angeles and Metro 


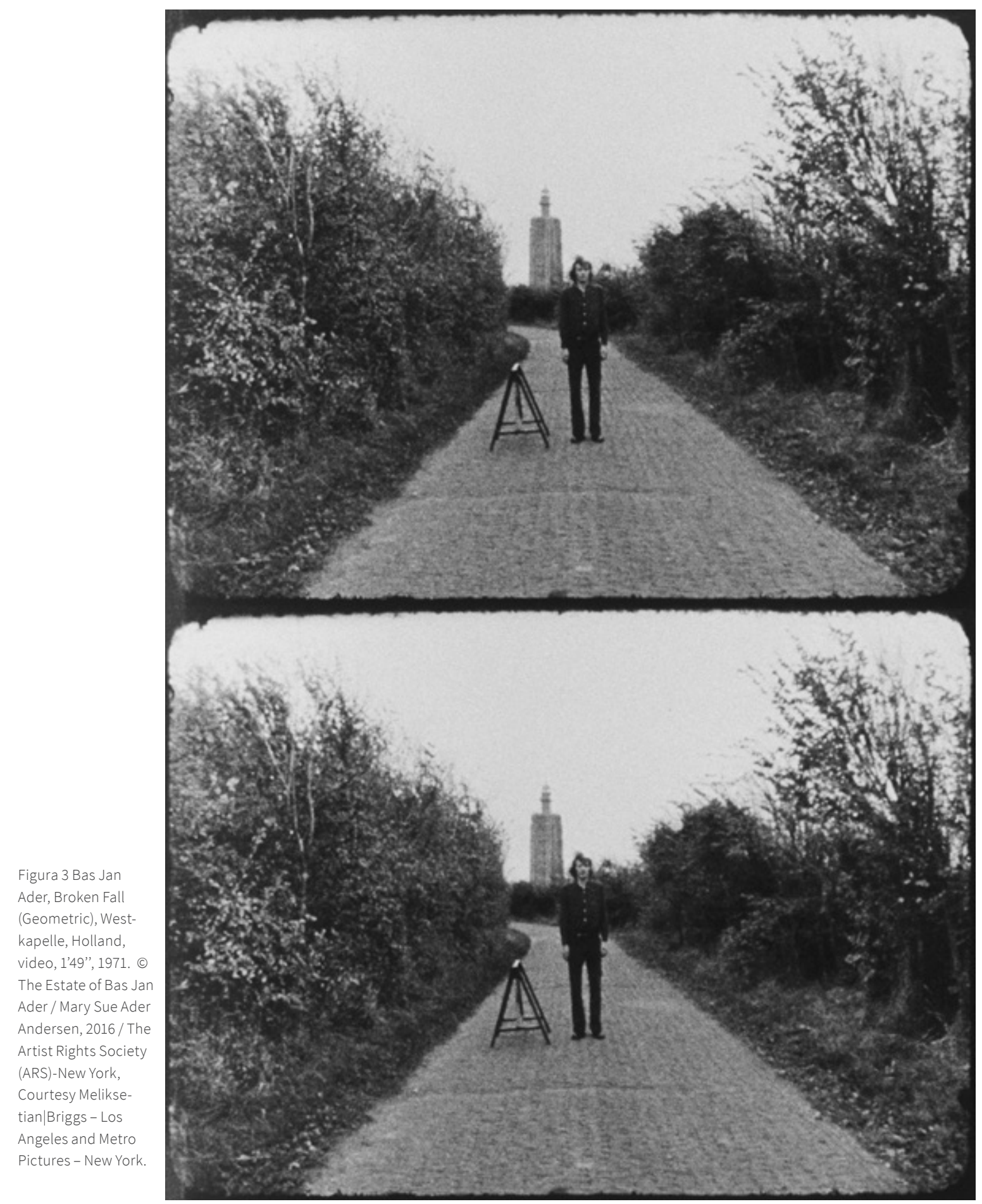



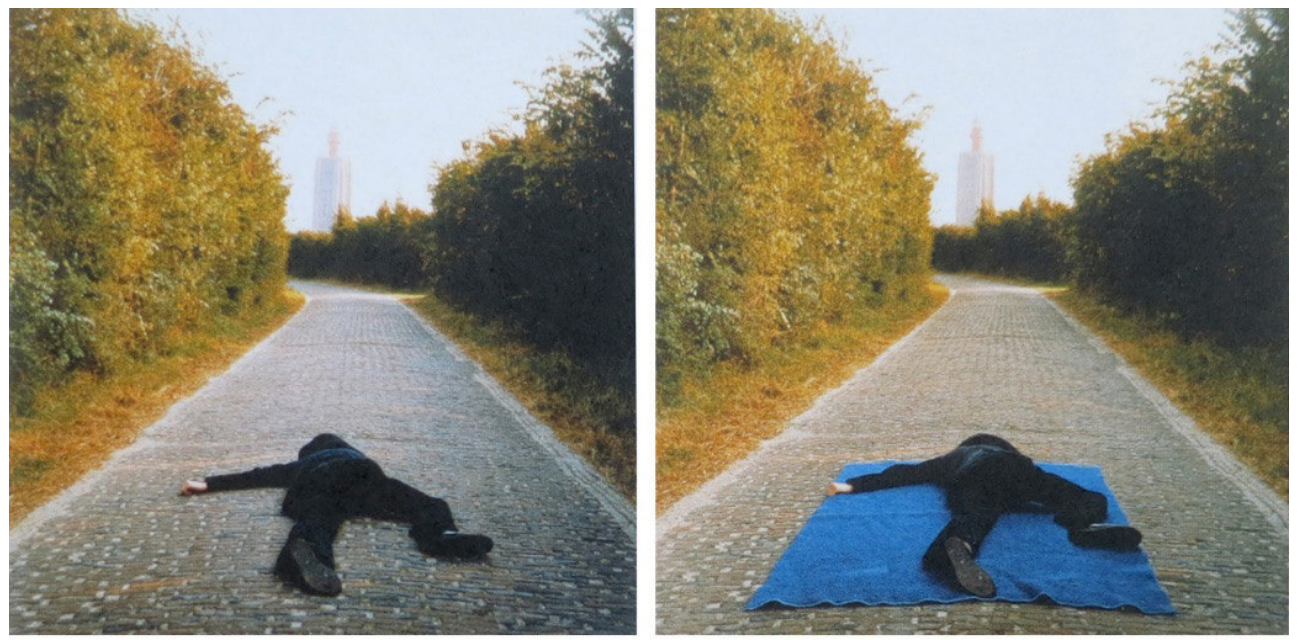

Figura 4 Bas Jan Ader, On The Road to a New Neo Plasticism, Westkapelle, Holland, 1971, four c-type prints, each $30 \times 30 \mathrm{~cm}$. (c) The Estate of Bas Jan Ader / Mary Sue Ader Andersen, 2016 / The Artist Rights Society (ARS)-New York, Courtesy Meliksetian|Briggs - Los Angeles and Metro
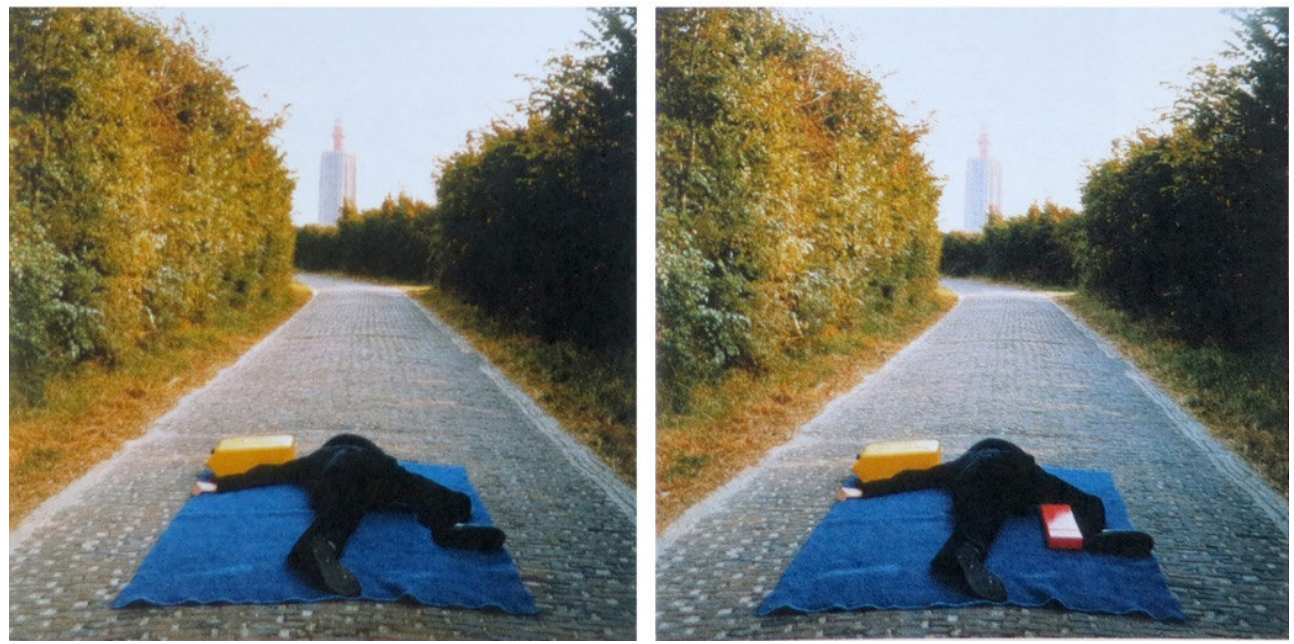

res- com uma sensibilidade humorística árida.

Nem todos os trabalhos de Ader são divertidos como os filmes Fall, mas o humor de sua arte foi em muito subestimado. I'm Too Sad to Tell You foi o título de três trabalhos separados com o mesmo tema e imagética; o primeiro, uma fotografia de 1970; o segundo, um cartão postal enviado aos amigos e aos que conheceu posteriormente no mesmo ano; o último, um filme de três minutos gravado no ano 1971. Tematicamente, I'm Too Sad to Tell You é discutivelmente seu trabalho menos engraçado. Todas as peças

mostram em close uma imagem recortada de Ader derramando lágrimas por nenhum motivo aparente. Ader descreveu a versão gravada como um de seus filmes da série Falls, ainda que sejam as lágrimas que obedeçam a lei da gravidade ao invés do corpo do artista (Van Garrel 1972: 48). Em 1972 Ader explicou que o trabalho foi sua reação à cultura "he-man" da Califórnia (ibid.: 49). Poderia esse ser um choque de cultura de um holandês fora do país? Talvez I'm Too Sad to Tell You tenha mais humor que aparenta em um primeiro olhar. A sátira aqui pode ser en- 


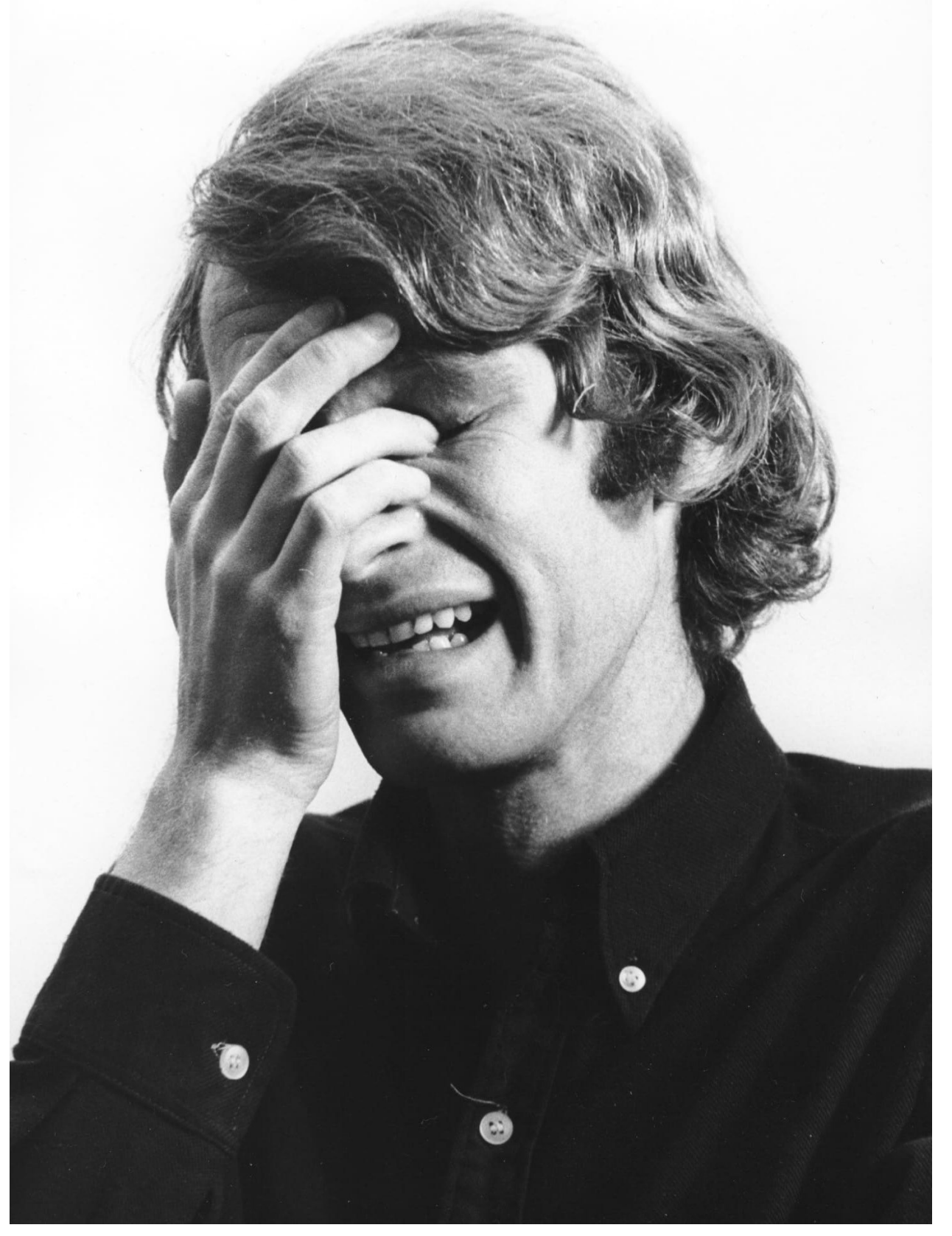

Figura 5 Bas Jan Ader, I'm Too Sad to Tell You, video 16mm, 3'21', 1971. @ The Estate of Bas Jan Ader / Mary Sue Ader Andersen, 2017 / The Artists Rights Society (ARS), New York. Courtesy of Meliksetian | Briggs, Los Angeles. 
Posicionei Ader dentro de uma moldura conceitual do pós-guerra da arte conceitual humorística que prevaleceu na Holanda e Califórnia, locais em que ele viveu e estudou. Usando teorias do humor e da identidade, demonstrei como suas piadas estavam intrinsecamente ligadas à contextos sociais em ambos os lados do Atlântico e argumentei que a identidade imprecisa do artista como vista em seu senso de humor é, de fato, um aspecto central de sua obra. Para ler o humor satírico na obra de Ader, que ressoa devido a incongruência na qual se enraíza seus site specific, os estudos sobre este artista devem olhar para a identidade binacional de Ader. Seu trabalho final, In Search of the Miraculous, é uma continuação de sua prática artística: perdido no mar entre os Estados Unidos e a Holanda, ele fisicamente reivindicou a posição desempenhada na criação de sua arte.

\section{Referências}

Andriesse, Paul (ed.). 1988. Bas Jan Ader: Kunstenaar. Amsterdam: Openbaar Kuntbezit.

Baldessari, John, Ann Goldstein and Rudi Fuchs.2011. "John Baldessari: Your Name in Lights - A Conversation Between John Baldessari, Ann Goldstein, and Rudi Fuchs." Stedelijk Museum Amsterdam, June 5.

Beenker, Erik. 2006. "Bas Jan Ader (1942-1975 Missing at Sea): The Man Who Wanted to Look Beyond the Horizon." In Bas Jan Ader: Please Don't Leave Me. Rotterdam Boijmans Van Beunningen.

Bell, Larry and Ann Goldstein. 2013. "Forum: Larry Bell and Ann Goldstein.” Stedelijk Museum Amsterdam, April 18.

Critchley, Simon. 2002. On Humour. $1^{\text {st }}$ ed. New York: Routledge.

Daalder, Rene.2008. Here Is Always Somewhere Else. DVD. Cult Epics.

Van Garrel, Betty.1972. "Bas Jan Ader's tragiek schuilt in een pure val." Haagse Post. January 5. Huizinga, Johan.1971. Homo Ludens: A Study of the Play-Element in Culture. Boston: Beacon Press.

International Federation of Film Archives.1998. The Slapstick Symposium: May 2 and 3, 1985, the Museum of Modern Art, New York, $41^{\text {st }}$ FIAF congress ed. By Eileen Bowser. Brussels. Belgium: Federation International des Archives du Film.

Jan Ader, Bas.1961. "Nederlander Exposeert in Whashington” Het Vaderland, April 24.

Morreal, John.2009. Comic Relief: A Comprehensive Philosophy of Humor. 1st ed. Chichester Uk and Malden, MA: Wiley-Blackwell DOl:10.1002/9781444307795.

Nahuizen, Bob.1961. "Amerika bracht basajan (19) uit Groningen onverwacht success" Het Vrije Volk, july 26.

Otterspeer, Willem.2011. Reading Huizinga. Translated by Beverly Jackson. Amsterdam: Amsterdam University Press.

Roberts, james. 1994. "The Artist Who Feel from Grace with the Sea." Frieze 17 (August): 3237.

Sefermann, Ellen, Jorg Heiser and Susan Hiller: 2008. Romantic Conceptualism. Bilingual Edition Bielefeld: Kerber.

Steenbergen. R.1993. "Bas Jan Ader" NRV Handelslad, March 5

Timmerman, Els.1993. "Op zoek naar het wonder” HP/De Tijd, July 9.

Verwoert, Jan.2006. Bas Jan Ader: In Search of the Miraculous. London: Afterall Publishing.

Wolfe, Charles.2010. "California Slapstick." In Slap Comedy, ed by Tom Paulus and Rob King, 169-190. New York: Routledge. 